\title{
Interactions of Tech Bindings with AT Boot Toe Inserts: Part I, Binding Toe-Piece Mechanics
}

\author{
Jeffrey R. Campbell, Irving S. Scher, David Carpenter, Bruce J. Jahnke, \\ and Randal P. Ching
}

\begin{abstract}
Alpine touring (AT) is a subdiscipline of alpine skiing where skiers ascend and descend snow slopes under their own power. Specialized equipment has been developed for AT skiing, including Tech/Pin bindings that rely on metal inserts molded into AT boots to rigidly couple the boot to the binding. The current lack of standardization has resulted in significant variation in tech insert geometry between boot manufacturers. It is hypothesized that the constraint forces from the tech binding on AT boots are highly sensitive to variations in tech insert geometry.

The dimensions of tech inserts in toe region of AT boots were measured from five manufacturers' boots. The constraint force applied by the toe pieces throughout their travel was measured quasi-statically using custom-built fixture on ten models of tech bindings from five manufacturers. In addition, the retention and release characteristics for an applied twisting torque were measured for the AT boots in the Tech/Pin binding toe pieces using an ASTM F504 test apparatus. Linear statistical models were developed to predict the measured retention-release behavior using the clamping force and tech insert geometry as predictor variables. The relative importance of each predictor variable from the linear model was then calculated.

The compressive forces applied to the AT boots were significantly different between bindings for the same boot, but not significantly different for the AT boots
\end{abstract}

\footnotetext{
J.R. Campbell $(\bowtie) \cdot$ R.P. Ching

Applied Biomechanics Laboratory, Department of Mechanical Engineering, University of Washington, 205 NE Northlake Way, Suite 100, Seattle, WA 98105, USA

e-mail: jrc24@washington.edu

\section{I.S. Scher}

Applied Biomechanics Laboratory, Department of Mechanical Engineering, University of Washington, 205 NE Northlake Way, Suite 100, Seattle, WA 98105, USA

Guidance Engineering and Applied Research, 205 NE Northlake Way,

Suite 100, Seattle, WA 98105, USA

D. Carpenter

DRC Services LLC, 5327 SW Manning Street, Seattle, WA 98116, USA

B.J. Jahnke

K2 Sports, 4201 6th Ave S, Seattle, WA 98108, USA
} 
in any particular binding $(p<0.001)$. Across all AT boots tested, the twisting release torque was not significantly different between bindings for a given boot $(p=0.81)$; however, significant differences in release torque were found between boots in any particular binding (two-way ANOVA, Tukeys Post Hoc, $p<0.001$ ). Boot dimensions at the toe had the largest influence on release torque $(\sim 85 \%)$ while the compressive force had the smallest influence $(\sim 15 \%)$.

Tech/Pin binding toe pieces are sensitive to small changes in tech insert geometry. This study only examined toe-piece kinematics and forces of tech bindings. Based on the data presented, a companion study will test Tech/Pin boot-binding systems with both the toe and heelpieces.

Keywords Skiing $\bullet$ Alpine touring $\bullet$ Ski bindings $\bullet$ Tech inserts

\section{Introduction}

Conventional alpine boots and bindings rigidly couple the skiers' boot to the ski to allow skiers to perform maneuvers while skiing downhill and to release the ski from the boot before loads to the lower leg become injurious. Alpine touring (AT) is a subdiscipline of skiing in which the skier uses the skis to ascend, traverse, and descend snow-covered terrain in the backcountry on unmaintained trails and sometimes rough terrain. Conventional alpine skiing equipment lacks functionality to allow skiers to ascend slopes under their own power during alpine touring. As a result, ski boot and binding manufacturers have developed specialized alpine touring equipment.

As a system, AT boots and bindings have two functional modes:

- Downhill (Ski) mode: the toe and heel of the boot are both rigidly fixed to the ski by the binding to allow the skier to perform maneuvers as they ski down snow slopes.

- Uphill (Walk) mode: the binding allows the heel of the boot to be decoupled from the ski, and the toe of the boot is free to pivot to allow the skier to walk up hill on skis, providing both flotation in deep snow and efficiency.

\subsection{Alpine Touring Bindings}

There are currently two alpine touring binding designs on the market, AT Frame Bindings and Tech/Pin bindings. AT Frame bindings are extrapolations of established alpine binding technology that incorporate an alpine binding toe piece and heelpiece mounted on a hinged chassis. A locking mechanism can secure the chassis 
to the ski for skiing and unlock for walking uphill. A hinge at the toe of the chassis allows the binding to pivot on the ski. The functional interface of AT frame bindings with AT boots is nearly identical to alpine bindings. AT frame bindings have release value settings that are controlled on the toe piece for twist and heelpiece for forward lean of the binding. These bindings are defined here for clarity but not the subject of the current study.

Tech/Pin bindings were developed by Fritz Barthell in the 1980s but were not widely adopted by AT skiers until the mid-2000s. Since the expiration of Barthell's patent in 2005 (Austria, NR. 376577), the growth in the AT boot sector has been explosive. Their name is derived from Barthell's first model, the "Low-Tech" binding. The boot-binding interface and retention-release mechanisms of these bindings function on completely different principles from alpine and AT frame bindings.

Commonly referred to as "mouse-trap bindings," Tech/Pin bindings have two stable equilibrium positions, open or closed (Fig. 1). The toe and heelpiece of the binding interface with metal inserts molded into the toe and heel of AT boots (Fig. 2). The toe piece commonly consists of a spring-loaded cam mechanism that has two conical pins that clamp into the inserts of the boot toe. For downhill skiing, the heelpiece commonly has two pins that engage into slots in the heel of the boot. For walking, the heelpiece pins can be retracted or rotated 90 degrees such that the rear pins do not engage the boot heel and the boot pivots about the toe piece to allow the skier to walk uphill (Fig. 2). Traditionally, the toe piece does not have any release value adjustment. In 2016, two tech-binding models incorporated release mechanisms in the toe and heelpieces to more adequately respond to combined loads. However, these models have little market share; tech-binding models with the largest market share control twist and forward lean release values are still controlled by the heelpiece.

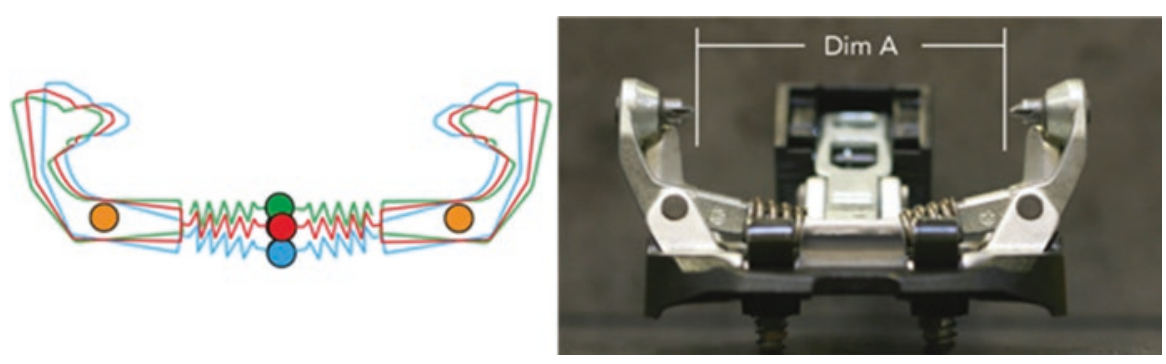

Fig. 1 (Left) Open and closed equilibrium positions of the Tech/Pin binding toe piece. (Right) Dim A is denoted as the pin-to-pin dimension when the binding is closed 

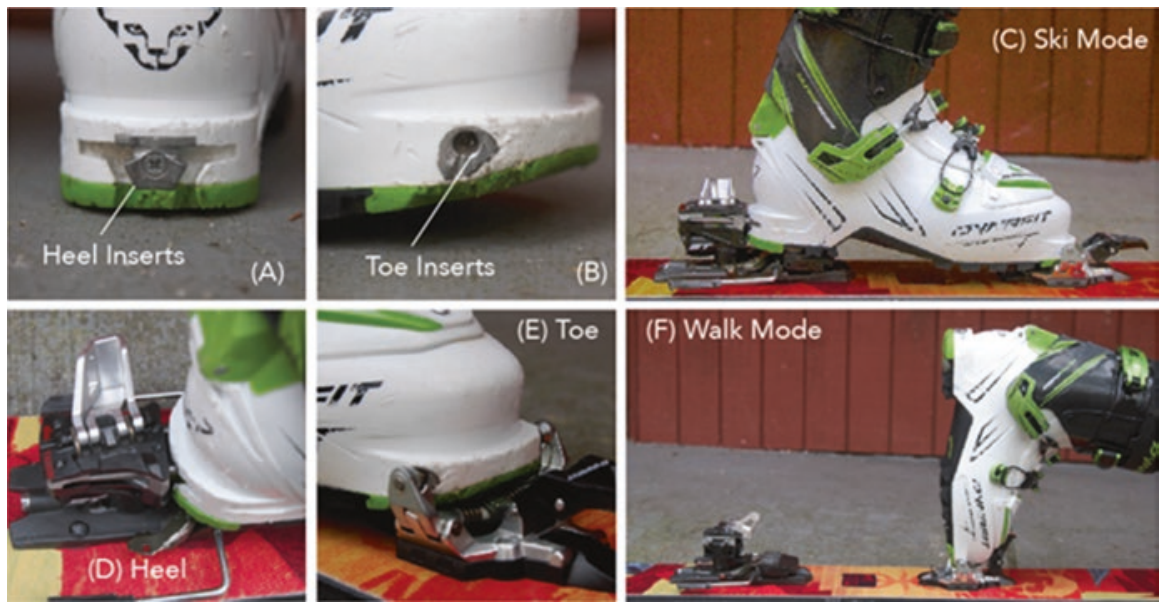

Fig. 2 (a) Heel inserts, (b) toe inserts molded into ski boots, (c) Tech/Pin binding-boot in ski model, with the toe and heel of the boot engaged, (d) heel of the boot engaged, (e) toe of the boot engaged, (f) walk mode with the heelpiece disengaged and only the toe piece of the binding engaged with the boot

\subsection{The State of Alpine Touring Equipment}

Mesolithic humans are estimated to have begun using skis for locomotion over snowy terrain as far back as 9000 BC $[1,2]$. However, the development and standardization of recreational AT equipment is still in its infancy compared to alpine skiing equipment. AT equipment is continually evolving in an effort to meet consumer demands for light-weight equipment that allows efficient uphill performance, while simultaneously providing reliable retention and release functionality skiers have come to expect from their conventional alpine ski equipment. However, the release-retention performance of many of these systems is a secondary design function to their uphill performance.

Safety standards have long been established for alpine ski equipment and have been proven to be effective in reducing the incidence of skiing-related lower leg injuries since the 1980s [3-6]. It wasn't until the early 2000s that international standards began to address the safety considerations of AT equipment with standards adapted from alpine ski equipment for AT equipment. The rapid pace of development of AT equipment has quickly outpaced the international standards organization's ability to address many new issues presented by evolving equipment designs. The interface geometry of AT boot soles with AT Frame bindings was standardized by ISO 9523:2006 and the retention-release requirements of AT bindings were defined by ISO 13992:2014 [7, 8]. However, these standards were largely derived from alpine boot-binding standards and have little bearing on how Tech/Pin bootbinding systems function.

No standard currently defines the interface geometry or properties of AT boots with Tech/Pin bindings. A common perception among consumers is that Tech/Pin bindings 
have unpredictable retention characteristics that produce inadvertent releases, which occur when a binding releases prematurely, when loads transferred from the ski to the skier are not at risk of injuring the lower leg. Consequently, many consumers ski with the toe piece of their Tech/Pin bindings in walk mode, which effectively locks out any release capability of the toe-piece mechanism. In the event of a fall with the toe piece in walk mode, the likelihood of the binding releasing is virtually nonexistent. The likelihood of a lower leg fracture using alpine ski bindings has been shown to increase three-fold if a binding does not release in a fall [9-11].

There are no known epidemiological studies for injury rates using AT equipment. However, examining injury rates in alpine skiing, inadvertent releases cause slightly less injuries than those caused by bindings not-releasing, 0.89 vs. $1.15 \%$ of all injuries, respectively [12]. Manufacturers have begun to recommend use of their boots with specific bindings and not others based on inter-manufacturer differences in boot geometry to address consumer perceptions of inadvertent releases. If consumer's perceptions are correct, then the risk of injury from an inadvertent release or from a non-release because the toe piece is locked out, is a concession of safety that must be addressed. To our knowledge, no previous work exists addressing the retention-release characteristics of AT boot-binding systems.

The purpose of the current study is to examine parameters critical to the retentionrelease performance of the AT boot-Tech/Pin bindings system and quantify the amount of inter-manufacturer variability in AT boot geometry and Tech/Pin binding performance. It is hypothesized that the dimensions of the boot inserts will be the largest source of release torque variability. From this analysis we hypothesize that several parameters can be identified for standardization to improve the reliability of the retention-release performance of Tech/Pin boot-binding systems.

\section{Methods}

When an AT boot is inserted into the toe piece of a Tech/Pin binding, the pins of the toe piece engage and come to rest at the inner most conical point of the inserts, defined as Dim A for the purposes of this study (Figs. 1 and 3). As load is applied to the ski, the pins of the toe piece will move apart, and the overall distance between them will increase until the toe piece snaps open.

\subsection{Boot Measurements}

Two linear dimensions, Dim A and Dim B, were measured three times each from the inserts on one pair of boots from nine boot models from seven manufacturers (Table 1) using a micrometer fitted with conical tips (Mitutoyo, Resolution $\pm 0.001 \mathrm{~mm}$ ). Dim A is defined as the inner most point between the two inserts (Fig. 3). Dim A is defined as the largest distance, in the horizontal plane, of the 


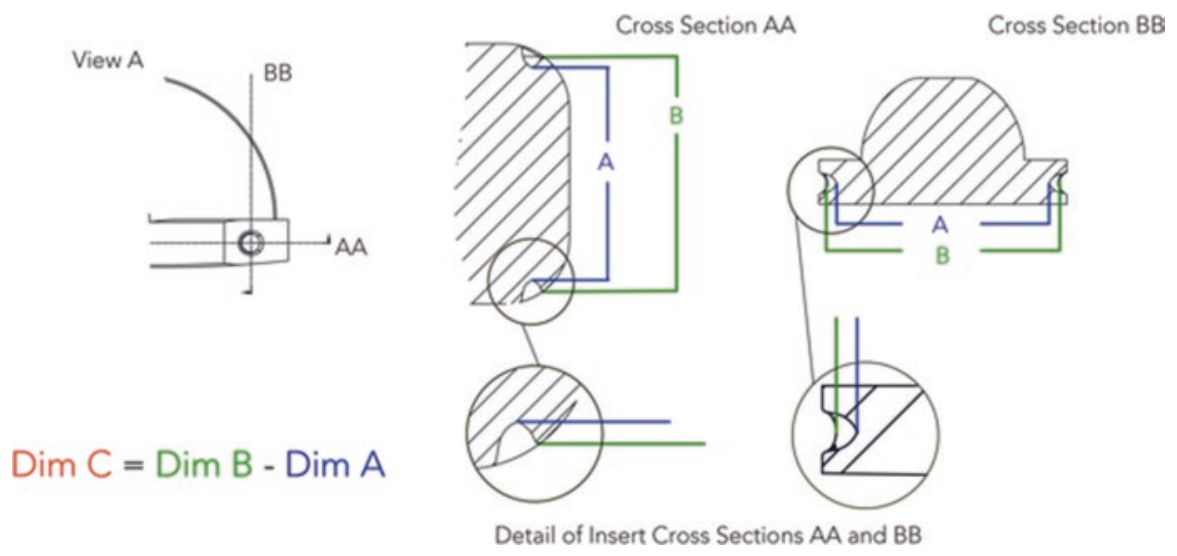

Fig. 3 AT boot dimensions measured at the toe inserts. View (A) is looking at a boot toe from the side. Cross section (AA) is a horizontal cut through the plane of the insert and boot sole. Cross section (BB) is a cut through the vertical plane of the boot toe; the view is towards the boot toe

Table 1 Descriptive statistics for three linear boot dimensions

\begin{tabular}{l|l|l|l|l}
\hline Manufacturer & Model & Dim A $(\mathrm{mm})$ & Dim B $(\mathrm{mm})$ & Dim C $(\mathrm{mm})$ \\
\hline $\mathrm{A}$ & A1 & $58.13 \pm 0.07$ & $63.80 \pm 0.38$ & $5.15 \pm 0.36$ \\
\hline $\mathrm{B}$ & B1 & $58.17 \pm 0.03$ & $63.24 \pm 0.20$ & $5.07 \pm 0.22$ \\
\cline { 2 - 5 } & B2 & $58.13 \pm 0.03$ & $63.69 \pm 0.01$ & $5.45 \pm 0.04$ \\
\hline $\mathrm{C}$ & $\mathrm{C} 1$ & $57.97 \pm 0.06$ & $63.91 \pm 0.07$ & $5.94 \pm 0.13$ \\
\cline { 2 - 5 } & C2 & $58.09 \pm 0.00$ & $64.24 \pm 0.02$ & $6.15 \pm 0.02$ \\
\hline $\mathrm{D}$ & D1 & $58.47 \pm 0.13$ & $62.24 \pm 0.23$ & $3.95 \pm 0.10$ \\
\hline $\mathrm{E}$ & E1 & $57.85 \pm 0.20$ & $63.66 \pm 0.28$ & $5.81 \pm 0.08$ \\
\hline $\mathrm{F}$ & F1 & $57.85 \pm 0.20$ & $63.37 \pm 0.13$ & $5.52 \pm 0.32$ \\
\hline M & G1 & $57.60 \pm 0.02$ & $63.15 \pm 0.02$ & $5.55 \pm 0.00$ \\
\hline$[$ Min, Max $]$ & & $58.03 \pm 0.24$ & $63.45 \pm 0.51$ & $5.42 \pm 0.63$ \\
\hline
\end{tabular}

insert on the anterior most position of the insert (Fig. 3). A third dimension, Dim C was calculated as the difference between Dim A and Dim C.

\subsection{Binding Measurements}

The force-displacement of the toe piece was measured using a custom forcedisplacement transducer (Fig. 4). The transducer incorporated a custom strain gagebased compression load cell (Range: $300 \mathrm{~N}$, Resolution: $0.3 \mathrm{~N} \pm 0.1 \mathrm{~N}$ ) and custom linear displacement transducer (Range $12 \mathrm{~mm}$, Resolution: $0.1 \mathrm{~mm} \pm 0.01 \mathrm{~mm}$ ) 


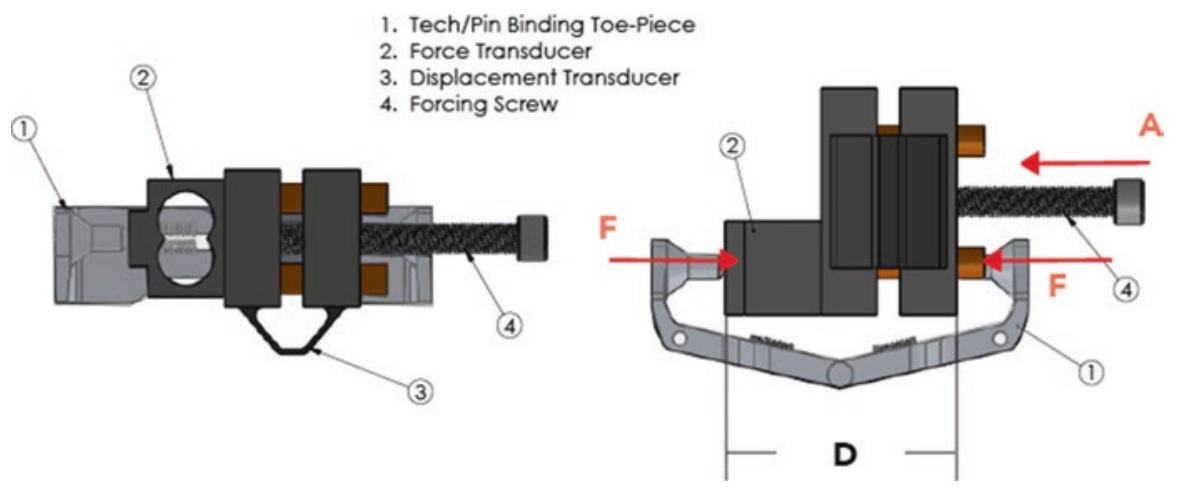

Fig. 4 Force-displacement transducer for measuring the clamping force-displacement curve of toe pieces. (A) The direction of the forcing bolt. $(F)$ Arrows show the resulting compressive force measured by the force transducer. $(D)$ The linear displacement of the binding pins measured by the displacement transducer

(J2A-06-S047G-350/SP62 Strain Gages, Vishay Measurements Group, Raleigh, NC). The custom force transducer was calibrated against a NIST-traceable six-axis load cell (Model 4526, Humanetics, Plymouth, MI) and the custom linear displacement transducerwas calibrated using a micrometer(Mitutoyo, Resolution $\pm 0.001 \mathrm{~mm}$ ). The force-displacement transducer incorporated a forcing screw mechanism to push the pins of the toe piece from the closed to open position while measuring the corresponding force-displacement relationship (Fig. 4). Force-displacement was measured on a total of 10 pairs of bindings from five manufacturers using a 16-bit data acquisition device while data were sampled at $250 \mathrm{~Hz}$ (SLICE NANO, Diversified Technical Systems, Seal Beach, CA). Tests were repeated six times on each binding toe piece.

\subsection{Release Torque Measurements}

The release characteristics of Tech/Pin boot-binding systems were tested in a laboratory setting using a lower leg surrogate that conformed to standards ISO 9462:2012 Appendix B [5] and ASTM F504-05 [13] (Fig. 5). The ten models of Tech/Pin bindings measured in Sect. 2.2 was mounted to their own test skis; all test skis were the same make, model, and $167 \mathrm{~cm}$ in length (AMP Rx, K2 Sports, Seattle, USA). Five models of AT boots measured in Sect. 2.1 (models A1, B1, C2, D1, E1 from Table 1) with boot sole lengths between 306 and $310 \mathrm{~mm}$ were prepared for testing. In order to measure the effect of boot design features, it was necessary to create a rigid coupling between the portion of the boot that interacts with the ski binding and a torque transducer. To this end, each test boot shell was cut below the pivot point of the upper shell and an aluminum adapter plate was secured to the foot area by filling 


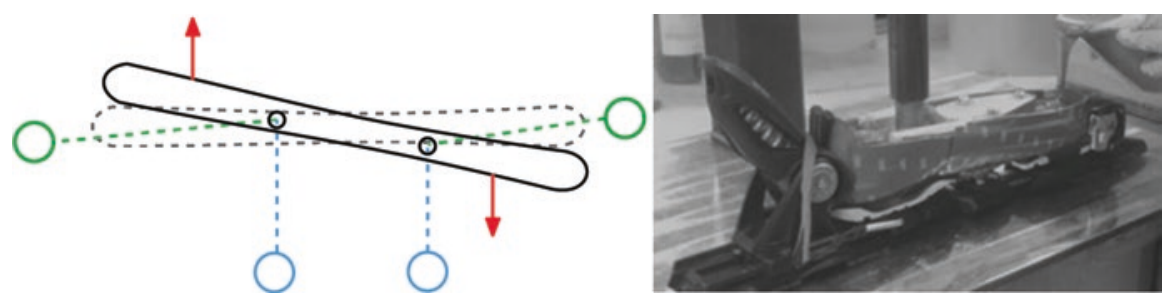

Fig. 5 Schematic of test apparatus that conforms to ASTM F504-05. The system applied forces (red arrows) to the ski using a motor-driven system of cables and pulleys. A load cell measures the torque on the simulated leg along the axial and transverse axes

the interstitial space with aluminum-filled epoxy (Rencast ${ }^{\circledR}$ 4037, Huntsman, The Woodlands, TX) (Fig. 5).

Ski/boot/binding systems were rigidly affixed to a transducer located in a lower leg surrogate via the adapter plate mounted in the boot; torque was applied to the ski using a system of motors, cables, pulley, and pneumatics which is measured by the transducer about the axial and transverse axes, as defined in ISO 9462-2012 (Fig. 5). All bindings released at very small angular displacements; therefore, a correction for the torque was not necessary. The range of the load cell was $\pm 400 \mathrm{Nm}$ (resolution: $0.29 \mathrm{Nm}$ ) and $\pm 700 \mathrm{Nm}$ (resolution: $0.17 \mathrm{Nm}$ ) along the axial and transverse axes. The load cell was calibrated against a NIST-traceable six-axis load cell (Model 4526, Humanetics, Plymouth, MI) and had less than $0.5 \%$ error at full scale. The data were collected at 1,000 Hz using a 16-bit data acquisition system (Model 6210USB, National Instruments, Austin, TX) with a $200 \mathrm{~Hz}$ low-pass, anti-aliasing filter. Labview 14.0 software (National Instruments, Austin, TX) was used to collect and filter digitally the data using with a four pole, zero phase shift, low-pass Butterworth filter with a cut-off frequency of $10 \mathrm{~Hz}$. A pure twisting couple, or torque, was applied to the ski with only the toe piece engaged in the ski position. Tests were performed dry, at $21^{\circ} \mathrm{C}$.

\subsection{Statistical Analysis}

Two-way ANOVAs were employed to test for statistical differences in constraints between bindings and boots, with a significance level of 0.05 .

\subsubsection{Multiple Linear Regression (MLR) Analysis}

Independent variables quantified from boot-binding constraints were used predict release torque in multiple linear regression (MLR) models ( $\boldsymbol{R}$, Foundation for Statistical Computing, Vienna, Austria, Fox, 2003). Data were centered about their mean and scaled by one standard deviation. The Kolmogorov-Smirnov test was employed to test for skewness [14]. MLR analyses were used to predict release 
torque based on unique combinations of independent variables for each load case. The likelihood ratio test compared models using different independent variables and tested for interactions between independent variables. Variance inflation factors (VIF > 5) were used to identify regressors with high collinearity [15]. Regressors were not used if they were not significant contributors to the model, with a significance level of 0.05 , or if they were redundant.

\subsubsection{Relative Contribution of Regressors to MLR Models}

The percent contribution to variation in release torque of each regressor in the MLR models was calculated using the $l m g$ metric from the relaimpo statistical package in $\boldsymbol{R}$ [16]. The $\operatorname{lmg}$ metric normalizes $R^{2}$ to $100 \%$ and the contribution of each regressor is calculated as a percentage of the $R^{2}$ from the linear model. The variance of percent contribution was calculated by bootstrapping the MLR models at 1000 bootstrap intervals, holding the regressors fixed and bootstrapping the residuals. The $95 \%$ bootstrap confidence intervals for regressors are reported.

\section{Results}

\subsection{Boots}

Descriptive statistics for measured dimensions of AT boot inserts are tabulated in Table 1. The distribution of measurements of Dim A, Dim B, and Dim C were positively (Dim A: 0.849) and negatively skewed (Dim B: -0.147, Dim C: -1.12), respectively (Fig. 6). However, skewness was not significant enough to require data transforms according to a Kolmogorov-Smirnov test. The variation in Dim A, \pm
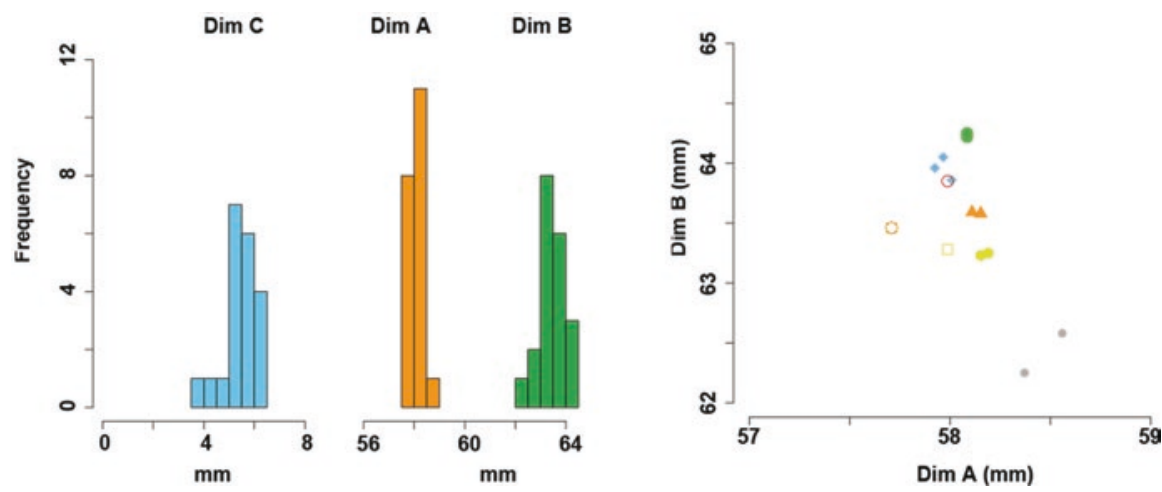

Fig. 6 Histogram of the distribution of Dim A, Dim B, and Dim C. Dim A vs. Dim B from nine boot models $(r i g h t)$. No trend or scaling of Dim A vs. Dim B is apparent, meaning Dim C varies across manufacturers 
$0.24 \mathrm{~mm}$, and Dim B, $\pm 0.51 \mathrm{~mm}$, appeared to contribute to tolerance stacking as the standard deviation in the Dim C dimension, $\pm 0.73 \mathrm{~mm}$, is approximately equal to the sum of the standard deviations of Dim A and Dim B.

\subsection{Bindings}

Force-displacement curves were generated for ten binding models from five manufacturers. Each curve showed significant variation in magnitude (Fig. 7a). Three representative clamping force-displacement curves are shown in Fig. 7 with the standard deviation from six repeated measurements of the force-displacement curve. The peak clamping force each binding was capable of generating varied significantly between models, ranging from $125 \mathrm{~N}$ up to $225 \mathrm{~N}$.

\subsection{Boot-Binding Compressive Force}

In Fig. 7, the points corresponding to Dim A for all boots measured lie on the uphill side of the force-displacement curve. Their location on this curve represents the amount of initial compressive force holding the boot in the binding. The positive slope of the curve results in differences in the magnitude of the preload applied to different boots, depending on the value of Dim A for a given boot. To release from

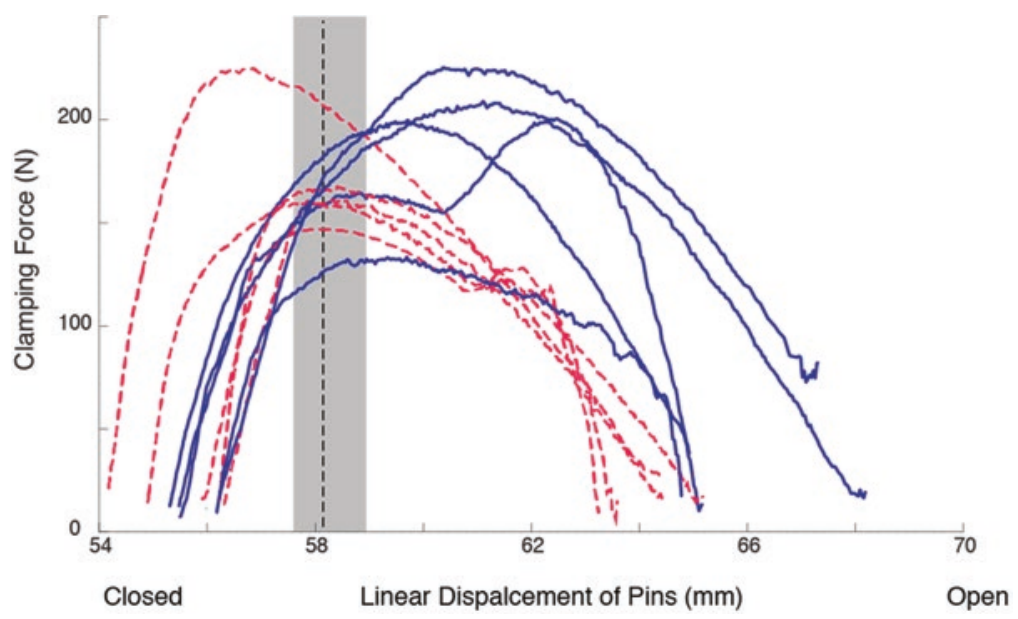

Fig. 7 Average force-displacement curves from all toe pieces measured moving from the closed position (left) to open position (right). The shaded rectangle delineates where Dim A from the nine boots measured lie on each force-displacement curve. Dashed lines indicate bindings where the boots lie on the curve past the binding's energy barrier. Solid lines indicate bindings where boots lie on the curve before the energy barrier 
the toe piece, these loads transmitted from the ski to the boot must overcome the energy barrier that corresponds with the peak of the force-displacement curve, moving from left to right in Fig. 7.

Curves shown in Fig. 7 with dashed lines are significantly different; their shape indicates that the toe piece closes on all boots at points along the curve that are already past the peak, or energy barrier, of that particular binding. As the pins of the toe piece open in response to loads transmitted from the ski to the boot, the binding toe piece will apply a smaller and smaller compressive force until the toe piece snaps open.

An analysis of variance on the clamping force yielded significant variation between bindings, $F(9,170)=80.69, p<0.001$. A post hoc Tukey test showed significant differences between all but 39 of the clamping forces generated by five of the binding toe pieces were significantly different from the remaining five (two-way ANOVA, Tukey's Post Hoc Test, $p<0.001$ ).

\subsection{Twisting Release Torque: Toe Piece Only}

An analysis of variance on the release torque yielded significant variation among boots and bindings, $F(39,140)=12.94, p<0.001$. A post hoc Tukey test showed significant differences in release torque in all but three boots (Fig. 8). A post hoc Tukey test also revealed the release torque from one binding toe piece to be significantly different from six other bindings (Fig. 8).

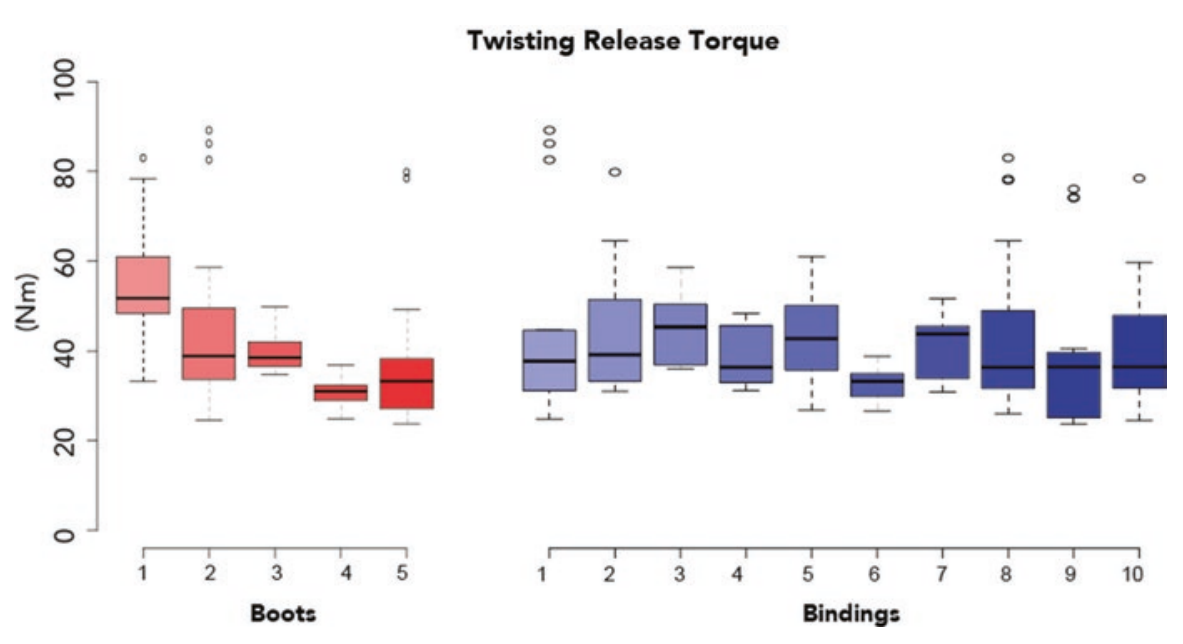

Fig. 8 Boxplots of release torque of the toe piece of bindings grouped by boots (L) and bindings (R) 


\subsection{Predicting Release Torque from Boot-Binding Constraints}

With independent variables of clamping force and boot dimensions, Dim A and Dim C, a significant MLR model was found for all binding toe pieces $(F(4,175)=22.55)$ that accounted for approximately $34 \%$ of the variance in release torque for all bindings (Multiple- $R^{2}=0.340$, Adjusted $-R^{2}=0.325, p<0.001$ ). However, significant MLR models were found for each individual binding toe piece that accounted for approximately $84.7 \% \pm 19.1 \%$ of the variance of Pure Twist release torque (Appendix, Table A.1).

The MLR models predicted the boot dimensions, Dim A and Dim C control $\sim 85 \%$ of the variability in release torque in each binding toe piece (Table 2, Fig. 9). In contrast, the clamping force exerted by the binding on the boot accounts for only $\sim 15 \%$ of the variability in release torque. A significant interaction between the starting positions of the pins, Dim A, and the amount of displacement required to release in twist, Dim C, was found 20.4\% [8.8\%, 32\%]. Finally, the clamping force from the binding contributed the least amount to variance in release torque $14.9 \%$ $[13.1 \%, 16.7 \%]$. Results from the MLR predict that increases in Dim A will decrease the release torque and increases in Dim $\mathrm{C}$ will increase release torque (Appendix, Table A.2).

Table 2 Percent relative contribution and the 95\% CIs [LL, UL] of boot-binding constraints to release torque variation for a pure twist release

\begin{tabular}{|c|c|c|c|c|c|c|}
\hline Binding & $\operatorname{Dim} A$ & Dim C & DimAIDimC & $\begin{array}{l}\text { Clamping } \\
\text { force }\end{array}$ & $R^{2}$ & $p$ \\
\hline 1 & $\begin{array}{l}22.2 \% \\
{[20.9,23.7]}\end{array}$ & $\begin{array}{l}18.8 \%[17.8, \\
19.9]\end{array}$ & $9.9 \%[8.7,11.1]$ & $\begin{array}{l}48.7 \%[47, \\
50.8]\end{array}$ & 0.995 & $<0.001$ \\
\hline 2 & $\begin{array}{l}26.2 \% \\
{[23.6,28.1]}\end{array}$ & $\begin{array}{l}35.4 \%[31.7, \\
38.4]\end{array}$ & $\begin{array}{l}10.5 \%[7.2, \\
13.7]\end{array}$ & $\begin{array}{l}28 \%[24, \\
31.1]\end{array}$ & 0.976 & $<0.001$ \\
\hline 3 & $\begin{array}{l}25.4 \% \\
{[23.5,27.9]}\end{array}$ & $\begin{array}{l}44.0 \%[39.1, \\
50.2]\end{array}$ & $4.6 \%[1.7,9.9]$ & $\begin{array}{l}21 \%[16.2, \\
27.8]\end{array}$ & 0.930 & $<0.001$ \\
\hline 4 & $\begin{array}{l}33.9 \% \\
{[33.1,34.8]}\end{array}$ & $\begin{array}{l}46.1 \%[44.7, \\
47.6]\end{array}$ & $7.7 \%[6.6,8.8]$ & $\begin{array}{l}12 \%[11, \\
13.4]\end{array}$ & 0.996 & $<0.001$ \\
\hline 5 & $\begin{array}{l}33.1 \% \\
{[26.2,44.2]}\end{array}$ & $\begin{array}{l}33.5 \%[25.4, \\
44.7]\end{array}$ & $\begin{array}{l}10.4 \%[4.3, \\
20.5]\end{array}$ & $\begin{array}{l}11.7 \%[8.6, \\
18.6]\end{array}$ & 0.841 & $<0.001$ \\
\hline 6 & $\begin{array}{l}8.2 \%[5.6, \\
11.8]\end{array}$ & $\begin{array}{l}9.3 \%[6.3, \\
13.3]\end{array}$ & $66.4 \%[60.2,72]$ & $\begin{array}{l}13.3 \%[11.6, \\
16]\end{array}$ & 0.961 & $<0.001$ \\
\hline 7 & $\begin{array}{l}22.9 \% \\
{[18.6,28.0]}\end{array}$ & $\begin{array}{l}37.5 \%[29.2, \\
46]\end{array}$ & $5.9 \%[1.2,14.1]$ & $\begin{array}{l}7.4 \%[4.3, \\
14.8]\end{array}$ & 0.709 & $<0.001$ \\
\hline 8 & $\begin{array}{l}31.4 \% \\
{[30.8,32.1]}\end{array}$ & $\begin{array}{l}53.1 \%[52, \\
54.3]\end{array}$ & $8.4 \%[6.7,10.1]$ & $\begin{array}{l}6.7 \%[6.3, \\
7.3]\end{array}$ & 0.995 & $<0.001$ \\
\hline 9 & $\begin{array}{l}26.4 \% \\
{[25.9,26.9]}\end{array}$ & $\begin{array}{l}58.3 \% \text { [57.1, } \\
59.6]\end{array}$ & $8.4 \%[6.9,10.1]$ & $6.5 \%[6,7.1]$ & 0.600 & $<0.001$ \\
\hline 10 & $\begin{array}{l}28.1 \%[8.4, \\
49.7]\end{array}$ & $\begin{array}{l}12.8 \%[4.9, \\
25.5]\end{array}$ & $\begin{array}{l}16.6 \%[1.2, \\
44.4]\end{array}$ & $\begin{array}{l}4.5 \%[1.1, \\
25]\end{array}$ & 0.467 & $<0.001$ \\
\hline
\end{tabular}


Relative Importance of Indepedant Variables, Averaged from 10 models, 1 model for each binding.
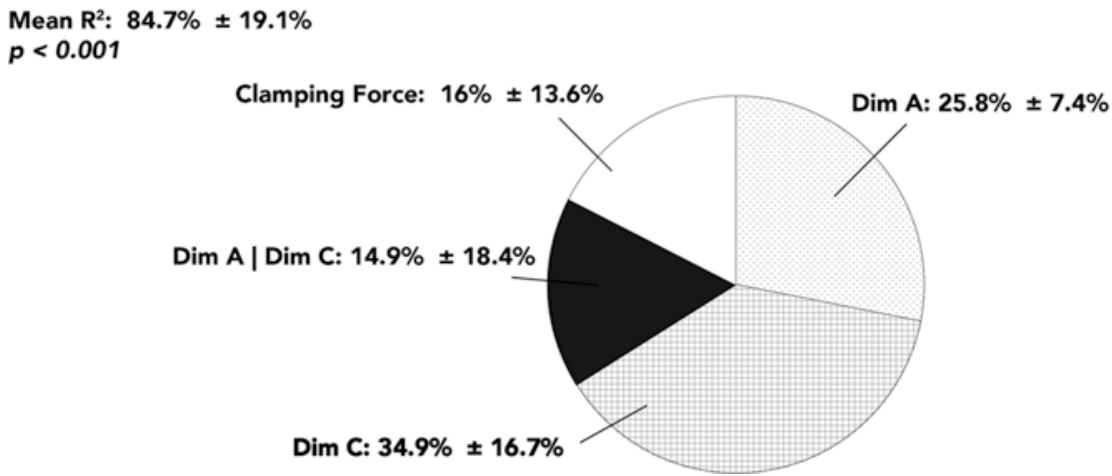

Fig. 9 Average relative importance of independent for the ten models from each binding

Dim A of the boot controls the initial clamping force; however, the potential energy to release is controlled by the slope of the force-displacement curve. The effect of the shape of the force-displacement curve has not been captured by the MLR models reported here. The toe piece with the highest compressive (clamping) force (Fig. 7) is very symmetrical and has a peak at a specific displacement value such that the values of Dim A lie on the positive slope of the curve.

In contrast, no matter what boot is used in the bindings corresponding dashed lines to in Fig. 7, there is no potential energy barrier to resist an inadvertent release. It follows that the available energy dissipation from each of these bindings is significantly different. Not only is the available potential energy, the area under each curve, very different, but also the variation in geometry found across all boots will alter considerably, the amount of energy a binding has to dissipate energy and prevent an inadvertent release. Furthermore, bindings represented by the dashed lines in Fig. 7 are closer to the middle equilibrium position shown in Fig. 1. The closer to this position the binding starts, the more unstable, and prone to prerelease it will be.

\section{Discussion}

International standards for alpine and AT boot geometry specify the geometry and tolerances for key interface dimensions to provide repeatable retention-release characteristics as consumers mix and match boots and bindings from different manufacturers. International ski boot standards specify allowable deviations from standardized boot geometry at the boot-binding interface that range between $0.5 \mathrm{~mm}$ and $2 \mathrm{~mm}$, or approximately 5-20\% of the target dimensions [5, 7].

Although the geometry of the AT boot toe inserts is not standardized, the variance measured in Dim A, Dim B, and Dim C between boots from ten manufacturers was relatively small, $\pm 0.25 \mathrm{~mm}, \pm 0.55 \mathrm{~mm}$, and $\pm 0.73 \mathrm{~mm}$, respectively. 
However, these small variations significantly altered the release torque of boots from the toe piece in twist. For example, in Fig. 9, mean release torque of Binding 2 from a sample of ten boots was $36.5 \mathrm{Nm}$, but the maximum torque recorded from a boot was $78.44 \mathrm{Nm}$, a $215 \%$ increase in release torque resulting from the use of different boots in the same binding. The MLR models predicted that $85 \%$ of this variability is a product of the small variations in boot geometry. These results highlight Dim A and Dim B as dimensions that highly influence the behavior of Tech/Pin boot-binding systems and that if standardized across manufacturers, a significant portion of the variation in release torque could be reduced. However, if a standard were to be developed for the insert geometry, the dimensions would likely require significantly tighter tolerances than what manufacturers are accustomed to.

The amount of variation in release torque found between boots and bindings may give credence to the perception among consumers that the release torque of Tech/ Pin boot-binding systems is variable and unpredictable. This may tempt skiers to lock out the release mechanism of the toe piece while skiing, particularly when the consequences of a fall could lead to serious injury or death. If the variability in release torque found in this study is an indicator of retention-release function of Tech/Pin bindings under skiing conditions, consumers may be at a higher risk of injury than they are accustomed to when using typical alpine skiing equipment, whether they lock out the release mechanism or not, due to an inadvertent release, or a non-release of a boot-binding system [12].

The current study has investigated the effect of geometric variations of boot insert geometry on release torque. Other factors not explored in the current study, but may also significantly affect release torque, include the surface roughness of the boot inserts, the hardness of the metal used in the binding pins and boot toe inserts, wear of these metal components over time, and debris that enters the system from being used in a mountainous environment.

This study was limited to an examination of the interactions of the boot-binding interface with the toe inserts of the boot and toe piece of the binding. The goal of this study was to understand the fundamental mechanics of the interaction of AT boot insert geometry and Tech/Pin binding toe pieces. The energy barriers of the toe piece have been reported from quasi-static tests. The slope of these quasi-static energy barriers provides valuable insight into the stability of a toe piece under dynamic loading; readers should note that under dynamic loading conditions, with the heelpiece engaged, the effects of boot geometry reported here might change. Our study examines the contribution of the toe piece to variation in release torque. Other than a pure twisting release, the current study did not examine any other load cases. Future studies will also examine how the contributions of the heelpiece and boot dimensions affect variations in release torque under other loading scenarios simulating forward and backward twisting falls. 


\section{Conclusion}

Anecdotally, skiers have reported locking the release mechanism of the binding toe piece due to a consumer perception that Tech/Pin boot-binding systems have unreliable retention performance. However, this exposes skiers to a higher risk of injury in the event of a fall when the binding should release from the boot. The consumer perception may have some merit since large variations in release torque were measured in this study. The consumer perception may have some merit since large variations in release torque were measured in this study stemming from the differences in boot insert geometry between manufacturers. If boot insert geometry were standardized across all manufacturers, the variation in release torque would decrease significantly.

\section{A. Appendix}

Table A.1 MLR fit metrics for release torque from ten bindings

\begin{tabular}{l|l|l|l|l}
\hline Binding & $F(4,10)$ & Multiple $R^{2}$ & Adjusted $R^{2}$ & $p$ \\
\hline 1 & 645.1 & 0.996 & 0.995 & $<0.001$ \\
\hline 2 & 143 & 0.983 & 0.976 & $<0.001$ \\
\hline 3 & 47.3 & 0.950 & 0.930 & $<0.001$ \\
\hline 4 & 892.5 & 0.997 & 0.996 & $<0.001$ \\
\hline 5 & 19.57 & 0.887 & 0.841 & $<0.001$ \\
\hline 6 & 86.41 & 0.972 & 0.961 & $<0.001$ \\
\hline 7 & 27.84 & 0.736 & 0.709 & $<0.001$ \\
\hline 8 & 693.1 & 0.996 & 0.995 & $<0.001$ \\
\hline 9 & 6.247 & 0.714 & 0.600 & $<0.001$ \\
\hline 10 & 4.066 & 0.619 & 0.467 & $<0.001$ \\
\hline
\end{tabular}


Table A.2 Scaled MLR coefficients $\left(\beta_{n}\right)$, standard errors (SE), and fit metrics for independent variables: Dim A, Dim C, the interaction of Dim A and Dim C (Dim AIDim C), and the clamping force $(\mathrm{CF})$

\begin{tabular}{|c|c|c|c|c|c|c|c|c|}
\hline \multirow{2}{*}{\multicolumn{2}{|c|}{ Bindings }} & \multicolumn{5}{|c|}{ MLR: Independent variables } & \multirow[b]{2}{*}{$R^{2}$} & \multirow[b]{2}{*}{$p$} \\
\hline & & \multirow{2}{*}{\begin{tabular}{|l|} 
Intcpt. \\
-0.29 \\
\end{tabular}} & \multirow{2}{*}{$\begin{array}{l}\text { Dim A } \\
0.44\end{array}$} & \multirow{2}{*}{\begin{tabular}{|l|}
$\operatorname{Dim} C$ \\
1.11
\end{tabular}} & \multirow{2}{*}{\begin{tabular}{|l|} 
DimAIDimC \\
$\mathbf{- 0 . 3 2}$ \\
\end{tabular}} & \multirow{2}{*}{\begin{tabular}{|l|} 
CF \\
-0.08 \\
\end{tabular}} & & \\
\hline All & $\beta n$ & & & & & & \multirow[t]{3}{*}{0.325} & \multirow[t]{3}{*}{$<0.001$} \\
\hline & SE & 0.10 & 0.06 & 0.15 & 0.14 & 0.09 & & \\
\hline & $p$ & $<0.001$ & $<0.001$ & $<0.001$ & $<0.001$ & 0.182 & & \\
\hline \multirow[t]{3}{*}{1} & $\beta n$ & -0.25 & -0.58 & -0.20 & -0.28 & -0.76 & \multirow[t]{3}{*}{0.996} & \multirow[t]{3}{*}{$<0.001$} \\
\hline & SE & 0.04 & 0.09 & 0.06 & 0.05 & 0.05 & & \\
\hline & $p$ & $<0.001$ & $<0.001$ & $<0.001$ & $<0.001$ & $<0.001$ & & \\
\hline \multirow[t]{3}{*}{2} & $\beta n$ & -0.52 & -0.20 & 1.06 & -0.59 & -0.09 & \multirow[t]{3}{*}{0.976} & \multirow[t]{3}{*}{$<0.001$} \\
\hline & SE & 0.09 & 0.11 & 0.19 & 0.14 & 0.10 & & \\
\hline & $p$ & $<0.001$ & 0.31 & $<0.001$ & $<0.001$ & 0.43 & & \\
\hline \multirow[t]{3}{*}{3} & $\beta n$ & -0.28 & 0.98 & 1.83 & -0.32 & -0.24 & \multirow[t]{3}{*}{0.930} & \multirow[t]{3}{*}{$<0.001$} \\
\hline & SE & 0.16 & 0.32 & 0.23 & 0.1642 & 0.18 & & \\
\hline & $p$ & 0.109 & 0.0124 & $<0.001$ & 0.080 & 0.211 & & \\
\hline \multirow[t]{3}{*}{4} & $\beta n$ & -0.43 & 2.12 & 2.78 & -0.49 & -0.14 & \multirow[t]{3}{*}{0.996} & \multirow[t]{3}{*}{$<0.001$} \\
\hline & SE & 0.04 & 0.08 & 0.05 & 0.04 & 0.04 & & \\
\hline & $p$ & $<0.001$ & $<0.001$ & $<0.001$ & $<0.001$ & $<0.001$ & & \\
\hline \multirow[t]{3}{*}{5} & $\beta n$ & -0.98 & -2.20 & 0.31 & -1.18 & 1.26 & \multirow[t]{3}{*}{0.841} & \multirow[t]{3}{*}{$<0.001$} \\
\hline & SE & 0.30 & 0.52 & 0.24 & 0.34 & 0.28 & & \\
\hline & $p$ & 0.009 & 0.002 & 0.226 & 0.006 & 0.001 & & \\
\hline \multirow[t]{3}{*}{6} & $\beta n$ & -1.83 & -4.09 & -1.0647 & -2.0661 & 1.85 & 0.961 & $<0.001$ \\
\hline & SE & 0.12 & 0.24 & 0.17 & 0.12 & 0.14 & & \\
\hline & $p$ & $<0.001$ & $<0.001$ & $<0.001$ & $<0.001$ & $<0.001$ & & \\
\hline 7 & $\beta n$ & -0.37 & 3.02 & 3.77 & -0.40 & -0.55 & 0.709 & $<0.001$ \\
\hline & SE & 0.14 & 0.36 & 0.40 & 0.12 & 0.11 & & \\
\hline & $p$ & $<0.001$ & $<0.001$ & $<0.001$ & $<0.001$ & $<0.001$ & & \\
\hline 8 & $\beta n$ & -0.43 & 3.26 & 4.20 & -0.48 & -0.49 & 0.995 & $<0.001$ \\
\hline & SE & 0.03 & 0.08 & 0.09 & 0.03 & 0.03 & & \\
\hline & $p$ & $<0.001$ & $<0.001$ & $<0.001$ & $<0.001$ & $<0.001$ & & \\
\hline 9 & $\beta n$ & -0.42 & 1.82 & 2.86 & -0.49 & -0.48 & 0.600 & $<0.001$ \\
\hline & SE & 0.03 & 0.03 & 0.06 & 0.06 & 0.03 & & \\
\hline & $p$ & $<0.001$ & $<0.001$ & $<0.001$ & $<0.001$ & $<0.001$ & & \\
\hline 10 & $\beta n$ & -0.62 & 1.32 & 1.79 & -0.72 & 0.44 & 0.467 & $<0.001$ \\
\hline & SE & 0.33 & 0.49 & 0.57 & 0.32 & 0.24 & & \\
\hline & $p$ & 0.090 & 0.023 & 0.010 & 0.050 & 0.099 & & \\
\hline
\end{tabular}

\section{References}

1. Sørensen M, Rankama T, Kankaanpää J, Knutsson K, Knutsson H, Melvold S, Eriksen BV, Glørstad H (2013) The first eastern migrations of people and knowledge into Scandinavia: evidence from studies of mesolithic technology, 9th-8th Millennium BC. Nor Archaeol Rev 46(1):19-56 
2. Formenti F, Ardigò LP, Minetti AE (2005) Human locomotion on snow: determinants of economy and speed of skiing across the ages. Proc R Soc B Biol Sci 272(1572):1561-1569

3. Warme R, WJ F, King JA, Lambert P, Cunningham KL, Vredenburgh AG, Cohen HH (1993) Proceedings of the human factors and ergonomics society 39th annual meeting-1995, pp. 1015-1019. J Saf Res 27(4):272-273

4. ISO 9462:2006(E) Alpine ski-bindings-requirements and test methods

5. SO 5355:2006(E) Alpine ski-boots-requirements and test methods

6. Johnson RJ, Ettlinger CF, Shealy JE (2007) Update on injury trends in alpine skiing. Ski Trauma Saf 5(10):11-22

7. ISO 9523:2008 Touring ski-boots for adults-interface with touring ski-bindings-requirements and test methods

8. ISO 13992:2006(E) Alpine touring ski-bindings—requirements and test methods

9. Finch CF, Kelsall HL (1998) The effectiveness of ski bindings and their professional adjustment for preventing alpine skiing injuries. Efficacite des fixations de ski et leur reglage par des professionnels pour la prevention des blessures en ski alpin. Sports Med 25(6):407-416

10. Bouter A, Knipschild LM, Volovics PG (1989) Binding function in relation to injury risk in downhill skiing.pdf. Am J Sports Med 17(2):226-233

11. Ekeland H, Holtmoen A, Lystad A (1993) Lower extremity equipment-related injuries in recreational skiers. Am J Sports Med 21(2):201-205

12. Shealy JE, Ettlinger CF, Johnson RJ (2005) Using signal detection theory as a model to evaluate release/retention criteria in alpine skiing. J ASTM Int 2(7):1-12

13. T. Methods (2005) ASTM F504-05: Standard test method for measuring the quasi-static release moments of alpine ski. ASTM F504, 1-12

14. Tohm Olofsson P, Andersson M (2012) Probability statistics and stochastic processes, vol 33. Wiley, Hoboken, NJ

15. O'Brien RM (2007) A caution regarding rules of thumb for variance inflation factors. Qual Quant 41(5):673-690

16. Grömping U (2006) Relative importance for linear regression in R: the package relaimpo. J Stat Softw 17(1):1-27

Open Access This chapter is distributed under the terms of the Creative Commons AttributionNoncommercial 2.5 License (http://creativecommons.org/licenses/by-nc/2.5/) which permits any noncommercial use, distribution, and reproduction in any medium, provided the original author(s) and source are credited.

The images or other third party material in this chapter are included in the work's Creative Commons license, unless indicated otherwise in the credit line; if such material is not included in the work's Creative Commons license and the respective action is not permitted by statutory regulation, users will need to obtain permission from the license holder to duplicate, adapt or reproduce the material. 